\title{
Fully-automatic synthesis of cine viability CMR images with minimal estimation error
}

\author{
Azza S Hassanein², Ayman M Khalifa ${ }^{2}$, El-Sayed Ibrahim ${ }^{\text {** }}$ \\ From 18th Annual SCMR Scientific Sessions \\ Nice, France. 4-7 February 2015
}

\section{Background}

A typical CMR exam includes cine, tagging, and delayed-hyperenhancement (DHE) sequences to produce images for evaluating global heart function, myocardial contractility, and viability, respectively. Usually, DHE imaging is conducted at mid-diastole. Nevertheless, obtaining cine DHE images is appealing to obtain simultaneous information about tissue viability and wall motion abnormality. In this study, we compare the performance of four image analysis techniques for generating the cine DHE images based on estimating tissue motion, validate the results on numerical phantom, and implement on in-vivo images.

\section{Methods}

A numerical phantom of a grid-tagged short-axis slice, that experiences cyclic deformation, was built to test the performance of four techniques for estimating the motion field used to generate the cine DHE images: harmonic phase (HARP)[1], and three optical-flow (OF) methods[2-4]: Lucas-Kanade optical-flow (LKOF), HornShunck (HSOF), and band-pass (BPOF). The generated motion fields are compared to the ground-truth motion.

Cine, DHE, and tagged images were acquired from four patients with myocardial infarction (MI) on 3T scanner. The motion field was estimated from the tagged images and used to reconstruct cine DHE images starting from the acquired (known) DHE image. Wall thickening was measured from both cine and generated DHE images. MI was determined using full-width at

half-maximum method. Circumferential strain was measured from the tagged images using Diagnosoft software.

\section{Results}

BPOF resulted in minimal tracking error compared to other techniques. The tracking accuracy of BPOF was close to HARP for intramyocardial points; however, it was significantly higher at the boundaries, where HARP failed to track the tag points. Fig.1 $(a, b)$ shows the tagging grid at end-diastole (initial frame) and tracking results at end-systole using HARP and BPOF. Fig.1(c-e) shows the average tracking error for points on the epicardium, endocardium, and mid-myocardium.

2 shows cine images, and corresponding synthesized DHE images (using BPOF), of the same slices at endsystole and end-diastole. The results showed strong correlation between wall thickening measured from both datasets $(R>0.7)$. Further, myocardial strain showed strong inverse correlation $(|\mathrm{R}|>0.8)$ with $\mathrm{MI}$ transmurality measured from the synthesized DHE images.

\section{Conclusions}

BPOF has minimal error in tracking taglines and measuring motion field, which can be used for generating cine DHE images. The generated cine DHE images may be important for comprehensive evaluation of the patient's condition, as they show simultaneous myocardial viability and wall motion abnormality on the same dataset without additional scan time or misregistration problems. 

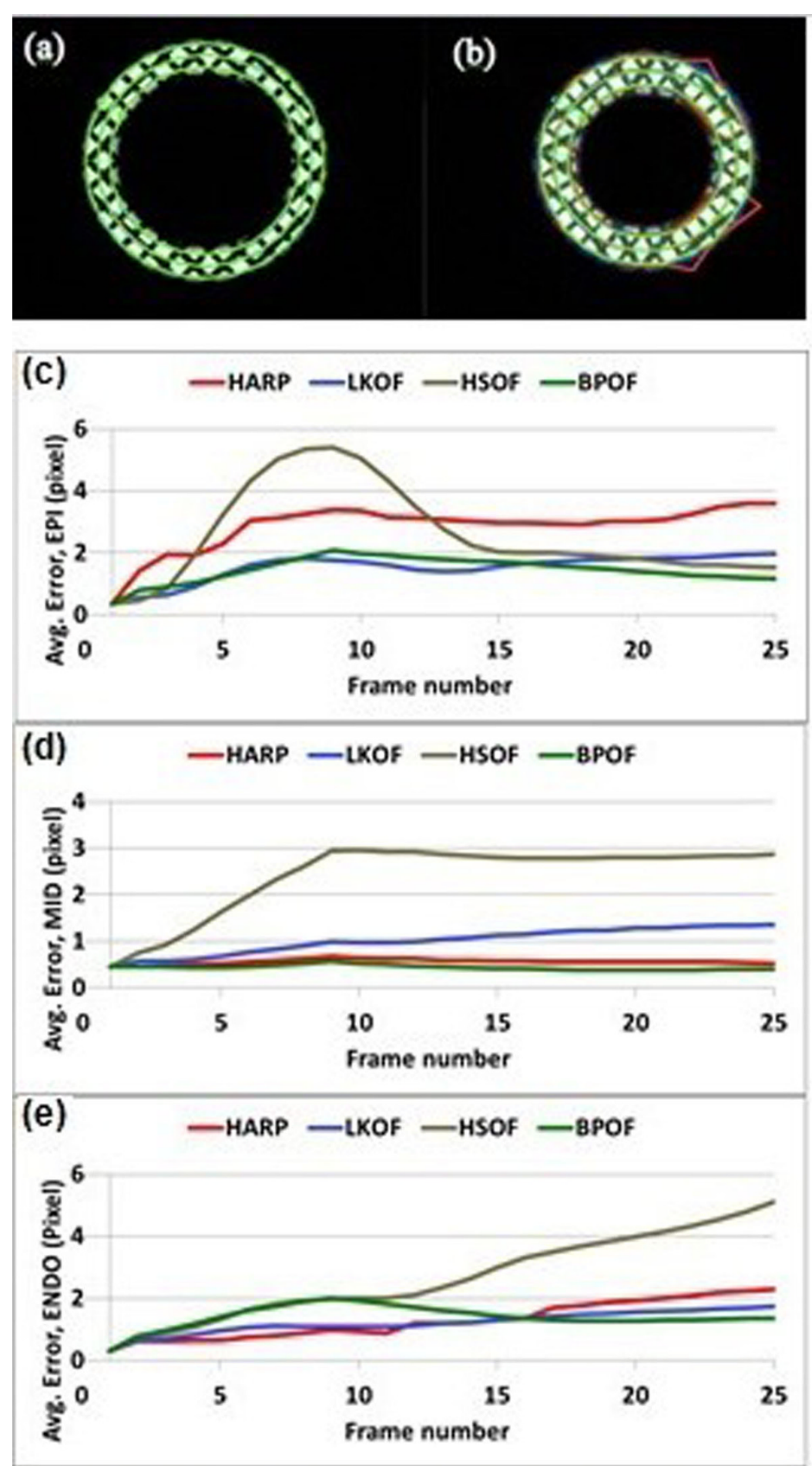

Figure 1 Phantom results. Grid-tagged images at (a) end-diastole and (b) end-systole, showing tracking results from BPOF (green) and HARP (red). Tracking error at (c) epicardium, (d) mid-myocardium, and (e) endocardium using HARP (red), LKOF (blue), HSOF (brown), and BPOF (green). BPOF shows lowest error amoung all methods, and outperforms HARP at the boundaries. 


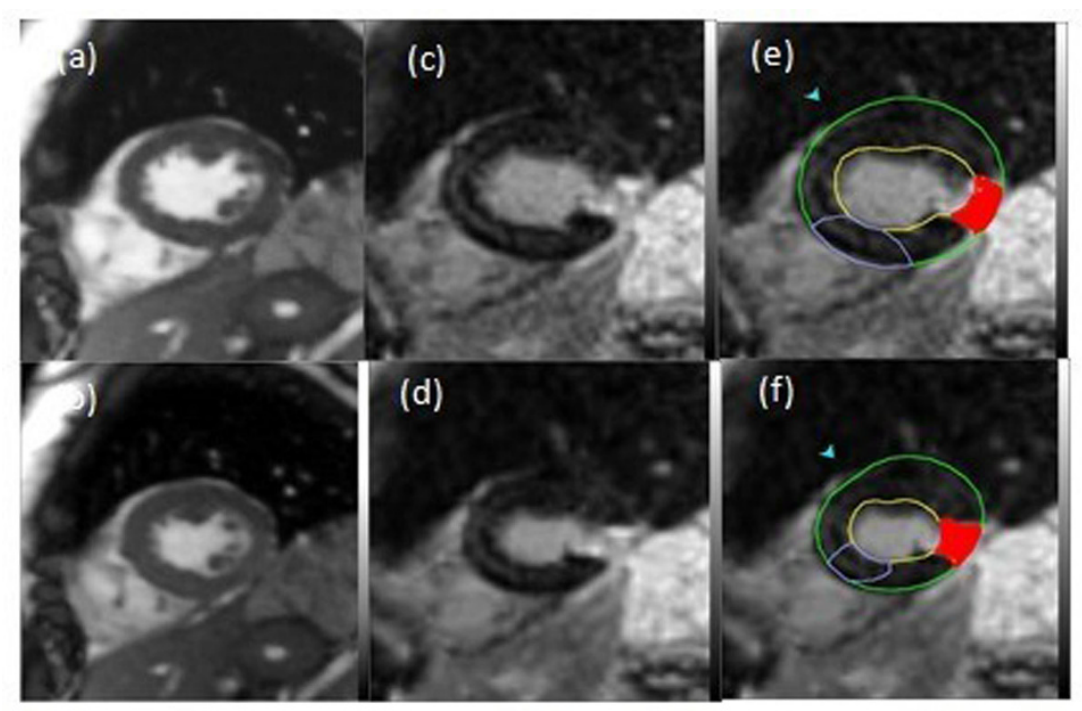

Figure 2 Cine images at (a) end-diastole and (b) end-systole with (c,d) corresponding synthetic DHE images. (e) and (f) show the DHe regions and wall thickness in corresponding synthetic DHE images.

\section{Funding}

N/A.

\section{Authors' details}

'University of Michigan, Ann Arbor, MI, USA. ${ }^{2}$ Helwan University, Cairo, Egypt.

Published: 3 February 2015

\section{References}

1. IEEE-TMI 19(3):186-202.

2. Intl J Comput-Vis $1111,12: 43-77$.

3. Artif Intel 1111, 17:185-204

4. Med Physic 1111, 27(1):108-118.

doi:10.1186/1532-429X-17-S1-P106

Cite this article as: Hassanein et al:: Fully-automatic synthesis of cine

viability CMR images with minimal estimation error. Journal of

Cardiovascular Magnetic Resonance 2015 17(Suppl 1):P106.

\section{Submit your next manuscript to BioMed Central} and take full advantage of:

- Convenient online submission

- Thorough peer review

- No space constraints or color figure charges

- Immediate publication on acceptance

- Inclusion in PubMed, CAS, Scopus and Google Scholar

- Research which is freely available for redistribution

Submit your manuscript at www.biomedcentral.com/submit
C Biomed Central 